\title{
Interleukin-6 and Interleukin-8 Secretions by Polarized Airway Epithelial Cells Infected by Normal and Small-Colony Variant Staphylococcus aureus Strains are Similar Despite Differences in Infection Levels
} Gabriel Mitchell, Myriame Lafrance, Brian G. Talbot and François Malouin*

Centre d'Étude et de Valorisation de la Diversité Microbienne (CEVDM), Département de Biologie, Faculté des Sciences, Université de Sherbrooke, QC, Canada, J1K $2 R 1$

\begin{abstract}
Staphylococcus aureus small-colony variants (SCVs) can efficiently infect non-professional phagocytes and are often referred to as facultative intracellular pathogens. The ability to hide and persist within host cells is likely to contribute to the development of chronic $S$. aureus infections such as those observed in the lungs of cystic fibrosis patients. Polarized human pulmonary Calu-3 cells were used to confirm that $S$. aureus small-colony variants (SCVs) persist within epithelial cells without exacerbating the innate immune response. Whereas all studied $S$. aureus strains significantly induced the secretion of Interleukin-6 (IL-6) and Interleukin-8 (IL-8) by Calu-3 cells 48 hours after cellular invasion, dead bacteria did not. Surprisingly, no difference in the secretion of these interleukins was detected between cells infected with normal and SCV strains despite the marked difference in infection levels. This study supports the hypothesis that despite their increased ability to persist inside epithelial cells, SCVs do not over activate the host immune response in comparison to normal strains. SCVs may thus help to perpetuate infection without exacerbation of the host immune response.
\end{abstract}

Keywords: Innate immunity; Intracellular infections; Cystic fibrosis; Small-colony variants

Abbreviations: AGR: Accessory Gene Regulator; CF: Cystic Fibrosis; CFU: Colony-Forming Unit; B D: Dead Bacteria; FBS: Fetal Bovine Serum; G-CSF: Granulocyte Colony-Stimulating Factor; IL-1 $\beta$ : Interleukin-1 $\beta$; IL-6:Interleukin-6; IL-8:Interleukin-8; INF$\gamma$ :Interferon- $\gamma$; IP-10: Inducible Protein 10kD; MCP-1: Monocyte Chemoattractant Protein-1; PBS: Phosphate Buffered Saline; SCVs (Or SCV): Small-Colony Variants; TNF-A: Tumor Necrosis Factor-A

Strains forming pin-point colonies and called small-colony variants (SCVs) are often isolated from Staphylococcus aureus chronic infections such as those encountered in the lungs of cystic fibrosis (CF) patients and also from osteomyelitis, septic arthritis and infections of orthopedic devices. Several SCVs are respiratory deficient strains that show a dysfunctional electron transport system. Such characteristic affects the growth rate, disrupts the proton motive force and decreases the susceptibility to aminoglycoside antibiotics, and also alters the expression of several virulence factors [1]. SCVs are now known to have an increased ability to form biofilms $[2,3]$ and to infect nonprofessional phagocytes [4]. This may promote the development of chronic infections by shielding the bacteria against the host immune system and the action of some antibiotics [4-6].

The distinct virulence profile of SCVs may result from the inability of the bacteria to properly activate the accessory gene regulator (agr) quorum-sensing system and/or by a sustained activity of the alternative transcription factor sigma B [7-9]. Interestingly, S. aureus activation of the agr system has been associated with the production of an innate immune response in both endothelial [10] and airway epithelial [11] cells. It was also demonstrated that normal $S$. aureus strains cause an inflammatory response in endothelial cells whereas SCVs did not [12]. In light of these results, we conducted a study aimed to evaluate the inflammatory response triggered by the infection of polarized human airway epithelial cells with normal and SCV strains, since these cells constitute the first line of defense against lung pathogens [13].

We used Calu-3 cells grown at the air-interface as our infection model. These cells are known to have many features of polarized and differentiated airway epithelial cells when grown in vitro [14-16] and should thus help in the study of interactions between the airway epithelium and S. aureus. The Calu-3 cell line (ATCC HTB 55) was cultured in eagle's minimum essential medium supplemented with $0.1 \mathrm{mM}$ minimum essential medium nonessential amino acids, $1 \mathrm{mM}$ of sodium pyruvate, $100 \mathrm{U} / \mathrm{ml}$ penicillin, $0.1 \mathrm{mg} / \mathrm{ml}$ streptomycin, 2.5 $\mu \mathrm{g} / \mathrm{ml}$ of Fungizone and $10 \%$ fetal bovine serum (FBS) at $37^{\circ} \mathrm{C}$ in $5 \%$ $\mathrm{CO}_{2}$ (Wisent, QC, Canada). Cell infection assays were performed as previously described with few modifications $[8,15,16]$. Briefly, cells were seeded at $1.5 \times 10^{5}$ cells/inserts on 12-wells transwells (Fischer, $\mathrm{ON}$, Canada) and cultured for 9 to 10 days in an air:liquid system. Approximately $1 \times 10^{6}$ hoescht-stained nucleus/insert were then observed. The complete medium in the basal compartments was replaced by the invasion medium (1\% FBS and no antibiotics) $18 \mathrm{~h}$ before assays. Inocula were prepared by suspending bacteria grown $20 \mathrm{~h}$ on brain heart infusion agar plates in ice-cold phosphate buffered saline (PBS). Bacteria were then washed three times in ice-cold PBS and suspended in the invasion medium supplemented with $0.5 \%$ bovine serum albumin at a density of approximately $4 \times 10^{8}$ colonyforming unit $(\mathrm{CFU}) / \mathrm{ml}$. Cells were washed twice with PBS and $250 \mu \mathrm{l}$ of the bacterial suspension was added to the apical side of each insert.

*Corresponding author: François Malouin, Département de Biologie, Faculté des Sciences, Université de Sherbrooke, 2500 Boul. Université, Sherbrooke, QC, Canada, J1K 2R1, Tel: (819) 821-8000, (61202); Fax: (819) 821-8049; E-mail: francois.malouin@usherbrooke.ca

Received August 08, 2011; Accepted October 10, 2011; Published October 28 2011

Citation: Mitchell G, Lafrance M, Talbot BG, Malouin F (2011) Interleukin-6 and Interleukin-8 Secretions by Polarized Airway Epithelial Cells Infected by Normal and Small-Colony Variant Staphylococcus aureus Strains are Similar Despite Differences in Infection Levels. J Bacteriol Parasitol 2:122. doi:10.4172/21559597.1000122

Copyright: ( 2011 Mitchell G, et al. This is an open-access article distributed under the terms of the Creative Commons Attribution License, which permits unrestricted use, distribution, and reproduction in any medium, provided the original author and source are credited. 
Citation: Mitchell G, Lafrance M, Talbot BG, Malouin F (2011) Interleukin-6 and Interleukin-8 Secretions by Polarized Airway Epithelial Cells Infected by Normal and Small-Colony Variant Staphylococcus aureus Strains are Similar Despite Differences in Infection Levels. J Bacteriol Parasitol 2:122. doi:10.4172/2155-9597.1000122

Page 2 of 3

Invasion was allowed for $3 \mathrm{~h}$, inserts were emptied and washed three times with PBS. Invasion medium supplemented with $20 \mu \mathrm{g} / \mathrm{ml}$ of lysostaphin (Sigma, ON, Canada) was then added to kill extracellular bacteria and the cells were further incubated for a varying amount of time. Following three washes with PBS, cells were detached with $100 \mu \mathrm{l}$ of trypsin $0.25 \%$ and lysed for $10 \mathrm{~min}$ by the addition of $400 \mu$ l of water containing $0.05 \%$ of triton X-100. Lysates were serially diluted 10 -fold and plated on agar for bacterial CFU determination. The intracellular localization of bacteria was confirmed by fluorescence microscopy using the anti- S. aureus antibody AB20920 (Abcam, MA, USA) and the olympus fluoview FV 300 confocal system $[15,16]$.

The strains CF07-L and CF07-S were previously compared for their ability to infect polarized Calu-3 cells [16]. CF07-L and CF07-S are genetically related $S$. aureus strains co-isolated from a CF patient, which respectively have a normal and a SCV phenotype [2]. Infection kinetics revealed no significant differences in the level of intracellular CFU recovered from Calu-3 cells infected with these strains 3, 9 and $24 \mathrm{~h}$ post-invasion, whereas a striking difference was found $48 \mathrm{~h}$ postinvasion [16]. This result was confirmed with another pair of geneticallyrelated non-SCV/SCV strains (CF1A-L and CF1D-S, respectively) co-isolated from another CF patient [2]. Figure 1a confirms that CFU recovered from cells infected by the SCV of both pairs of strains are markedly higher than those of their normal counterpart $48 \mathrm{~h}$ postinvasion (more than a $2 \log _{10}$ increase in magnitude).

In order to evaluate the immune response of Calu- 3 cells to $S$. aureus infections, combinations of flowcytomix ${ }^{\mathrm{TM}}$ simplex kits were used according to the recommendations of the manufacturer (eBioscience, San Diego, CA). The extent of granulocyte colony-stimulating factor (G-CSF), interleukin-1 $\beta$ (IL-1 $\beta$ ), IL-6, IL-8, Interferon- $\gamma$ (INF- $\gamma$ ), INF- $\gamma$ inducible protein $10 \mathrm{kD}$ (IP-10), monocyte chemoattractant protein-1(MCP-1) and tumor necrosis factor- $\alpha$ (TNF- $\alpha$ ) secretion by Calu-3 cells infected by $S$. aureus at 3, 9, 24 and 48 hours postinvasion was initially evaluated to establish detectable and reproducible thresholds (data not shown). Only IL- 6 and IL- 8 secretions at $48 \mathrm{~h}$ postinvasion were selected to compare the effect of different strains on the activation of the immune response because only these cytokines were significantly induced during the infection of Calu-3 cells by $S$. aureus, although the biological significance of the low IL- 6 secretion levels in these infected cells may be marginal. According to the manufacturer, the sensitivity of the method was of 1.2 and $0.5 \mathrm{pg} / \mathrm{ml}$ for IL- 6 and IL-8, respectively. As expected, treatment of cells with $100 \mathrm{ng} / \mathrm{ml}$ of TNF- $\alpha$ or $10 \mu \mathrm{g} / \mathrm{ml}$ of LPS for $48 \mathrm{~h}$ also stimulated IL- 6 and IL- 8 secretion (data not shown). The induction of the pro-inflammatory mediators IL- 6 and IL-8 in epithelial cells infected by $S$. aureus has also been reported by others $[11,13,17-19]$ and is thought to constitute a critical part of the lung immune response to bacterial pathogens [13].

The secretion of IL- 6 and IL- 8 was then measured from Calu- 3 cells infected with the normal and SCV strains CF07-L, CF07-S, CF1A-L and CF1D-S, and compared to that from non-infected Calu-3 cells. In addition, the immune response of cells exposed to approximately $1 \times 10^{8}$ CFU of heat inactivated CF07-l bacteria $\left(30 \mathrm{~min}\right.$ at $72^{\circ} \mathrm{C}$ ) was evaluated since live or dead $S$. aureus may not trigger the same response in host cells $[20,21]$. Figure $1 \mathrm{~b}$ and $1 \mathrm{c}$ show that all studied $S$. aureus strains induced IL- 6 and IL- 8 secretion in airway epithelial cells $48 \mathrm{~h}$ postinvasion in comparison to uninfected cells (one-way ANOVA followed by the Dunnett's post test), whereas dead bacteria had no effect on the cells (unpaired t-test). Surprisingly, no difference was observed in the extent of IL- 6 and IL-8 secretion by airway epithelial cells despite

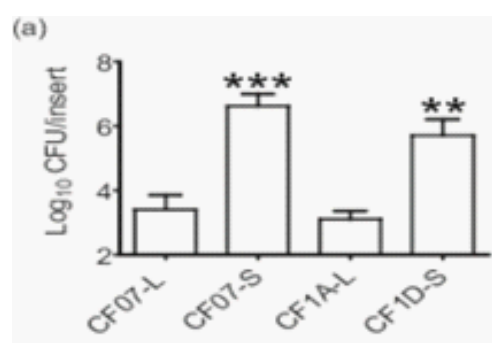

(b)

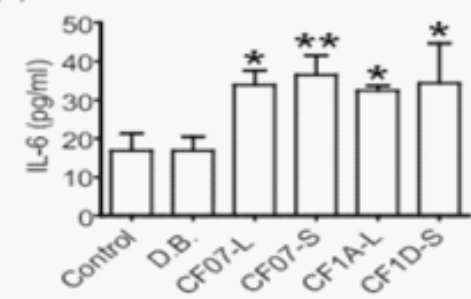

(c)

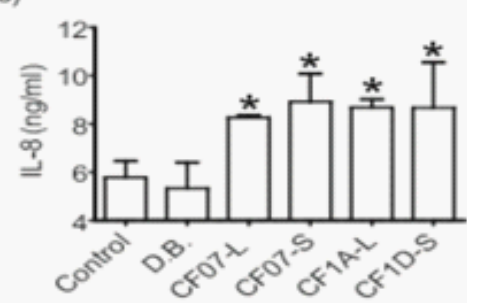

Figure 1: IL-6 and IL-8 secretions by polarized airway epithelial cells infected with normal and SCV strains are similar despite marked differences in infection levels. (A) Bacterial CFU recovered $48 \mathrm{~h}$ post-invasion from polarized Calu-3 cells infected with the S. aureus SCV strains CF07-S and CF1D-S and their normal counterparts CF07-L and CF1A-L, respectively. Significant differences between CFU recovered from cells for normal and SCV strains of each pairs are indicated $\left({ }^{* *}, P<0.01 ;{ }^{* * *}, P<0.001\right.$; unpaired t-test). Figures $1 \mathrm{~B}$ and $1 \mathrm{C}$ show the concentrations of IL- 6 and IL- 8 in the basal compartment of Transwells seeded with polarized Calu- 3 cells, respectively. Cells were either non-infected (untreated control), treated with dead bacteria (D.B.) or infected with the various strains CF07-L, CF07-S, CF1A-L and CF1D-S. The medium from the basal compartment of the Transwell was collected $48 \mathrm{~h}$ post-invasion for the measurement of IL-6 and IL- 8 concentrations. Significant differences between the control and the infected conditions are shown $(*, P<0.05$; **, $P<$ 0.01 ; one-way ANOVA followed by the Dunnett's post test). No difference between strains was revealed by a one-way ANOVA followed by the Tukey's post test. Results are from three independent experiments performed in duplicate.

their being infected with different $S$. aureus strains (one-way ANOVA followed by the Tukey's post test) and notwithstanding the markedly greater ability of SCV strains CF07-S and CF1D-S to persist $48 \mathrm{~h}$ postinvasion in comparison to their normal counterparts. Noteworthy, normal colony-forming bacteria were recovered at a low frequency 48 hours post-invasion from cells infected with SCVs. It is thus possible that the induction of IL- 6 and IL-8 secretions in SCV infected cells may have arisen by phenotypic switching during intracellular infections especially that the SCV strains used in this study are clinical isolates that have kept the natural ability to revert back to the normal phenotype

This study supports the hypothesis that SCVs do not particularly activate the host immune system despite their marked intracellular persistence $[4,12]$. This may help to explain why some infections caused by SCVs can be sustained asymptomatically for many years [22-24]. Tuchscherr, et al. [25] have recently proposed that the switch from the normal to the SCV phenotype and vice versa could be an integral part of the infection process. It is likely that the SCV phenotype can confer the ability to $S$. aureus to remain hidden inside 
Citation: Mitchell G, Lafrance M, Talbot BG, Malouin F (2011) Interleukin-6 and Interleukin-8 Secretions by Polarized Airway Epithelial Cells Infected by Normal and Small-Colony Variant Staphylococcus aureus Strains are Similar Despite Differences in Infection Levels. J Bacteriol Parasitol 2:122. doi:10.4172/2155-9597.1000122

Page 3 of 3

non-professional phagocytes for some periods of time until reversion to normal phenotype occurs and a new acute phase of infection begins. Therapeutic tools to tackle both the normal and persistent phenotypes seem implicitly needed [15].

This study was supported by a grant from Cystic Fibrosis Canada. G.M. Obtained the Alexander-Graham-Bell Graduate Scholarship from the Natural Science and Engineering Research Council of Canada and a doctoral research scholarship from the Fonds Québécois de la Recherche sur la Nature et les Technologies during the course of this study. The authors thank Nancy Dumais' laboratory members for technical assistance.

\section{References}

1. Proctor RA, von Eiff C, Kahl BC, Becker K, McNamara P, et al. (2006) Small colony variants: a pathogenic form of bacteria that facilitates persistent and recurrent infections. Nat Rev Microbiol 4: 295-305.

2. Mitchell G, Séguin DL, Asselin AE, Déziel E, Cantin AM, et al. (2010) sigma B-dependent emergence of small-colony variants and biofilm production following exposure to Pseudomonas aeruginosa 4-hydroxy-2-heptylquinolineN-oxide. BMC Microbiol 10: 33.

3. Singh R, Ray P, Das A, Sharma M (2010) Enhanced production of exopolysaccharide matrix and biofilm by a menadione-auxotrophic Staphylococcus aureus small-colony variant. J Med Microbiol 59: 521-527.

4. Sendi P, Proctor RA (2009) Staphylococcus aureus as an intracellular pathogen: the role of small colony variants. Trends Microbiol 17: 54-58.

5. Stewart PS (2002) Mechanisms of antibiotic resistance in bacterial biofilms. Int J Med Microbiol 292: 107-113.

6. Galli J, Ardito F, Calo L, Mancinelli L, Imperiali M (2007) Recurrent upper airway infections and bacterial biofilms. J Laryngol Otol 121: 341-344.

7. Kahl BC, Belling G, Becker P, Chatterjee I, Wardecki K, et al. (2005) Thymidinedependent Staphylococcus aureus small-colony variants are associated with extensive alterations in regulator and virulence gene expression profiles. Infect Immun 73: 4119-4126.

8. Moisan H, Brouillette E, Jacob CL, Langlois-Bégin P, Michaud S, et al. (2006) Transcription of virulence factors in Staphylococcus aureus small-colony variants isolated from cystic fibrosis patients is influenced by SigB. J Bacterio 188: 64-76.

9. Mitchell G, Lamontagne CA, Brouillette E, Grondin G, Talbot BG, et al. (2008) Staphylococcus aureus SigB activity promotes a strong fibronectin-bacterium interaction which may sustain host tissue colonization by small-colony variants isolated from cystic fibrosis patients. Mol Microbiol 70: 1540-1555.

10. Grundmeier M, Tuchscherr L, Bruck M, Viemann D, Roth J, et al. (2010) Staphylococcal strains vary greatly in their ability to induce an inflammatory response in endothelial cells. J Infect Dis 201: 871-880.

11. Ratner AJ, Bryan R, Weber A, Nguyen S, Barnes D, et al. (2001) Cystic fibrosis pathogens activate $\mathrm{Ca}^{2+}$-dependent mitogen-activated protein kinase signaling pathways in airway epithelial cells. J Biol Chem 276: 19267-75.
12. Tuchscherr L, Heitmann V, Hussain M, Viemann D, Roth J, et al. (2010) Staphylococcus aureus small-colony variants are adapted phenotypes for intracellular persistence. J Infect Dis 202: 1031-40.

13. Gómez MI, Prince A (2008) Airway epithelial cell signaling in response to bacterial pathogens. Pediatr Pulmonol 43: 11-19.

14. Grainger Cl, Greenwell LL, Lockley DJ, Martin GP, Forbes B (2006) Culture of Calu-3 cells at the air interface provides a representative model of the airway epithelial barrier. Pharm Res 23: 1482-1490.

15. Mitchell G, Gattuso M, Grondin G, Marsault E, Bouarab K, et al. (2011) Tomatidine Inhibits Replication of Staphylococcus aureus Small-Colony Variants in Cystic Fibrosis Airway Epithelial Cells. Antimicrob Agents Chemother 55: 1937-1945.

16. Mitchell G, Grondin G, Bilodeau G, Cantin AM , Malouin F (2011) Infection of Polarized Airway Epithelial Cells by Normal and Small-Colony Variant Strains of Staphylococcus aureus is Increased in Cells with Abnormal CFTR function and is influenced by NF-KB. Infect Immun. Epub ahead of print.

17. Sachse F, Becker K, von Eiff C, Metze D, Rudack C (2010) Staphylococcus aureus invades the epithelium in nasal polyposis and induces IL-6 in nasal epithelial cells in vitro. Allergy 65: 1430-1437

18. Fragaki K, Kileztky C, Trentesaux C, Zahm JM, Bajolet O, et al. (2006) Downregulation by a long-acting $\beta 2$-adrenergic receptor agonist and corticosteroid of Staphylococcus aureus-induced airway epithelial inflammatory mediator production. Am J Physiol Lung Cell Mol Physiol 291: L11-8.

19. Escotte S, Al Alam D, Le Naour R, Puchelle E, Guenounou M, et al. (2006) T cell chemotaxis and chemokine release after Staphylococcus aureus interaction with polarized airway epithelium. Am J Respir Cell Mol Biol 34: 348-354.

20. Haslinger-Löffler B, Kahl BC, Grundmeier M, Strangfeld K, Wagner B, et al. (2005) Multiple virulence factors are required for Staphylococcus aureusinduced apoptosis in endothelial cells. Cell Microbiol 7: 1087-1097.

21. Strindhall J, Lindgren PE, Lofgren S, Kihlstrom E (2002) Variations among clinical isolates of Staphylococcus aureus to induce expression of E-selectin and ICAM-1 in human endothelial cells. FEMS Immunol Med Microbiol 32: 227 235

22. Proctor RA, van Langevelde $P$, Kristjansson M, Maslow JN , Arbeit RD (1995) Persistent and relapsing infections associated with small-colony variants of Staphylococcus aureus. Clin Infect Dis 20: 95-102.

23. Kipp F, Ziebuhr W, Becker K, Krimmer V, Höß N, et al. (2003) Detection of Staphylococcus aureus by $16 \mathrm{~S}$ rRNA directed in situ hybridisation in a patient with a brain abscess caused by small colony variants. J Neurol Neurosurg Psychiatry 74: 1000-1002.

24. von Eiff C, Becker K, Metze D, Lubritz G, Hockmann J, et al. (2001) Intracellular persistence of Staphylococcus aureus small-colony variants within keratinocytes: a cause for antibiotic treatment failure in a patient with darier's disease. Clin Infect Dis 32: 1643-1647.

25. Tuchscherr L, Medina E, Hussain M, Volker W, Heitmann V, et al. (2011) Staphylococcus aureus phenotype switching: an effective bacterial strategy to escape host immune response and establish a chronic infection. EMBO Mol Med 3: 129-141. 